DOI: $10.5272 /$ jimab.2011171.146

Journal of IMAB - Annual Proceeding (Scientific Papers) 2011, vol. 17, book 1

\title{
ERYSIPELAS PENIS
}

\author{
Ilko Bakardzhiev ${ }^{1}$, George Pehlivanov ${ }^{2}$ \\ 1) Medical College, Medical University of Varna, Bulgaria \\ 2) Department of Dermatology and Venereology, \\ Medical University of Sofia, Bulgaria
}

\section{SUMMARY}

Erysipelas is an acute streptococcal skin infection. The most common localizations of the disease are the lower extremities, face and trunk. Venous insufficiency, stasis ulcerations, inflammatory dermatitis, dermatophyte infections, insect bites and surgical incisions are the most common points of entry. We present a case report of a 28 year old male with erysipelas penis, combined with non-gonococcal urethritis, treated successfully with Moxifloxacin.

Key words: Erysipelas penis, non-gonoccocal urethritis, moxifloxacin

\section{INTRODUCTION}

Erysipelas is an acute streptococcal bacterial infection of the skin. The most common localization is the lower extremities. A rare localization of the disease is to be found on the face, trunk, genitals and the perianal region. The most common pathogenic bacteria are Group $A$ в-hemolytic Streptococci but similar lesions can be caused by group B, C, and G. Atypical pathogens are Streptococcus pneumoniae, Klebsiella pneumoniae, Haemophilus influenzae, Enterobacteria, Yersinia enterocolitica, Pseudomonas aeruginosa, and Moraxella species which should be considered in resistant to the standard treatment cases. General symptoms and signs such as fever, chills, and malaise together with regional lymphadenopathy and laboratory findings including leukocytosis, elevated C-reactive protein (CRP), or erythrocyte sedimentation rate (ESR) are usually present. The diagnosis is based on the history, clinical findings, laboratory values and rarely microbiological culture results. A fiery red, tender, painful plaque with welldemarcated edges is the hallmark of the disease. Early diagnosis and proper treatment result in excellent prognosis.

\section{CASE REPORT}

We present a 28 years old man who complains of erythema, edema, pain in the penile region and high fever after sexual intercourse. The patient does not report any diseases of his partner. Two days later appeared urethral secretion. Upon physical examination we found fiery-red, well demarcated plaque with raised borders, phimosis and urethral secretion. [Fig 1, 2] The inguinal lymph nodes were enlarged bilaterally and painful on palpation. The laboratory tests showed increased ESR and leukocytosis. The serologic tests for sexually transmitted diseases (HIV, HBsAg, HCV, Syphilis, Herpes genitalis and Chlamydia trachomatis) were negative. The microbiologic culture from the urethral secretion determined growth of $\beta$-hemolytic Streptococci Group B. Moxifloxacin $400 \mathrm{mg}$ daily for 12 days resulted in full recovery of both the erysipelas and the urethritis.

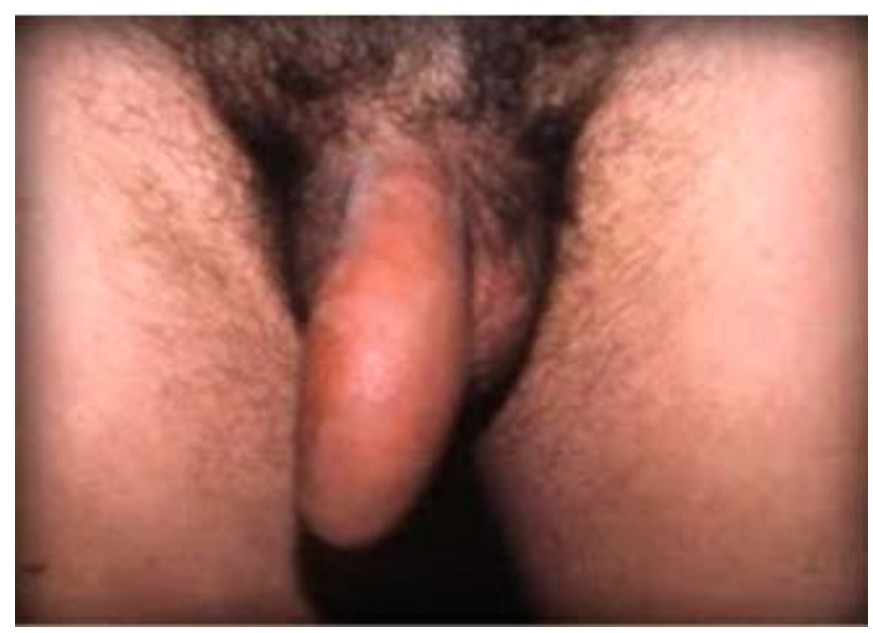

Fig. 1 Erysipelas penis, fiery-red plaque with raised, well demarcated borders

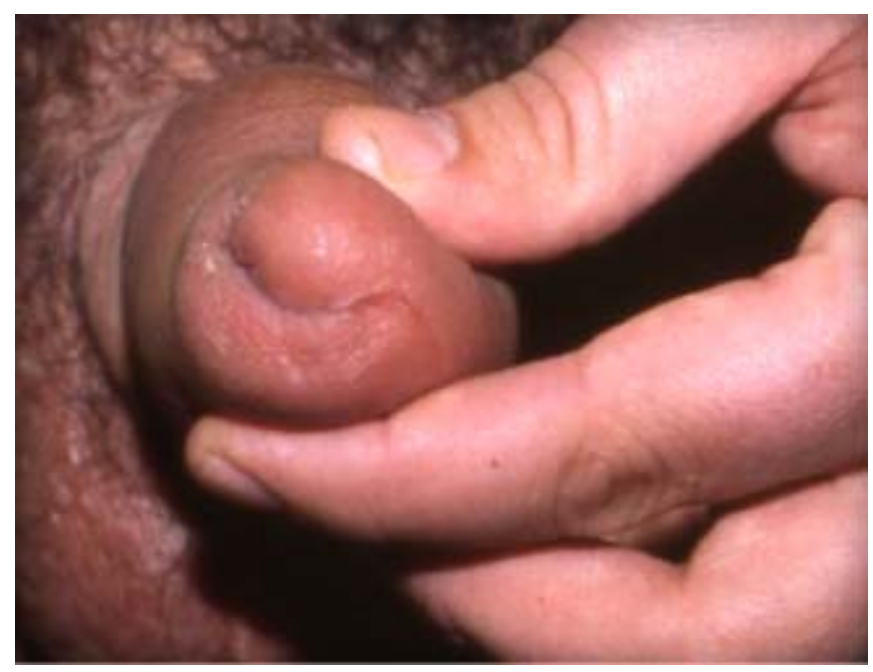

Fig 2 Phimosis and urethral secretions 


\section{DISCUSIONS}

Erysipelas on the male genitalia has a protracted course before starting antibiotic treatment. The anatomic specificity of the region can lead to the appearance of edema, which can be further complicated by trophic imbalances, the worst of them gangrene. [10]

Erysipelas penis can develop upon already existing lymphedema of the penis and scrotum. $[1,7]$ In the following case, upon initial examination we could not determine a preceding injury and entry point for the infection. It appeared de novo and is characterized by an acute onset.

Different traumas and wounds, as well as existing dermatoses in the genital area (mycoses, balanoposthitis, and genital herpes) are necessary for the development of infection. The clinical presentation comprises of local symptoms and general intoxication. [11] In the majority of cases the intoxication symptoms (fever, sleep disturbance, malaise) precede the appearance of inflammation. The affected area of the skin appears imbibed, itchy and burning. [5]

Quite a few authors in recent years report a change in the course of the disease - de novo erysipelas starts with localized pain in the affected area more often than with symptoms of general intoxication [12]. This has been confirmed by our own observations as well. There are a number of cases when the disease has a recurrent course which should prompt further investigation for Diabetes Mellitus. [8]

Erysipelas with such anatomic localization can have a variety of clinical presentations. The structure of the surrounding tissues determines the speed and distribution of the inflammation. [6] The main morphologic determinants are erythema and oedema, which rise above the surrounding intact skin. Erythema, as a rule, is an even looking structure. The edges though can have a different shape - saw tooth or arches, and can spread with different level of intensity over intact skin. The periphery can be raised above the remaining parts of the erythema. The skin is tight, warm and painful on palpation. The edema spreads beyond the erythema borders. Its severity depends on the localization of the inflammatory process. Its expression is strongest in the areas with loose connective tissue (genitals, eye lids, lips). The erythemobullous form of erysipelas is characterized by bullous lesions localized over the erythema, containing serous exudates. [2]

The erythemo-hemorrhaghic form is characterized by skin hemorrhages with different size. The bullous-hemorrhagic forms have bullae containing hemorrhagic and serous exudates.

The necrotizing erysipelas has hemorrhagic and serous exudates in the buli. The necrotizing erysipelas has skin necroses. Localization to one anatomic area is much more widely spread.

There are forms of erysipelas that spread beyond the affected area. Special clinical forms of the disseminated forms are the spreading (migrating) and metastatic erysipelas.

The migrating forms spread through the lymph and they present with spots of different sizes, connected with sheets of inflamed superficial lymph nodes.

The metastatic variants are rare; they spread through the blood, with the involvement of different areas of the skin not connected with each other. This form starts as a localized process and later develops into a disseminated one.

The differential diagnosis of genital erysipelas comprises the following other diseases: eczema (its acute forms), Contact allergic dermatitis, abscess, phlegmone and cellulitis.

The eczema is polymorphic, the erythema has vesicles, erosions, spot exudates, crusts and squamas. There is no infiltration, regional lymphadenitis, temperature and intoxication, typical for erysipelas.

Vesico-bulous forms of erysipelas must be differentiated from herpes genitalis.

The allergic contact dermatitis has well defined erythemo-oedema, often time s accompanied by vesicles and bullae, apart from the presence of itching and burning. The skin infiltration is not significant. The diagnosis is made easier when there is history of contact dermatitis with different irritants.

The abscess is a localized, while the phlegmone is a diffuse inflammation of the skin and subcutaneous tissue. The progression of the infection increases the symptoms of acute inflammation and general intoxication. In order to differentiate from erysipelas, the initial infiltrate must be followed by central fluctuation.

Cellulitis is an infection of the derma and hypoderm. It is characterized by lymphangitis, lymphadenitis and general symptoms of intoxication and very often erysipelas and cellulitis overlap.

Apart from the classical complications characteristic of male penile erysipelas, phymosis, paraphymosis, disuria, urethritis and enlarged inguinal lymph nodes are often present.

We have observed similar clinical picture as the one described. Serology for sexually transmitted diseases (HIV, $\mathrm{HBsAg}, \mathrm{HCV}$, Syphilis, and Genital Herpes) is mandatory for erysipelas of the penis.

$\beta$ lactamase producing Streptococci are the most common bacterial pathogen for erysipelas. Naturally, $\beta$ lactamase antibiotics (Penicillin) are the drug of first choice. Penicillin administered orally or intramuscularly is sufficient for most cases of classic erysipelas and should be given for duration of 10-20 days. If there is an allergy against Penicillin, first generation Cephalosporins or Macrolides (Erythromycin or Azithromycin) can be used. Cephalosporins should be used with caution in patients with a history of severe allergic reaction towards Penicillin, leading to anaphylaxis. $\beta$ lactamase resistant Penicillins (Oxacillin, Methicillin, Cloxacillin) are the drug of first choice in Streptococci resistant 
to Penicillin and are used in recurrent forms. Hospitalization and intravenous antibiotics are recommended in severe cases, newborns, elderly and the immunocompromised. [4]

We used Moxifloxacin $400 \mathrm{mg}$ daily for 12 days, which lead to complete recovery, both of erysipelas and urethritis.

Moxifloxacin is a fluoroquinolone - a girase inhibitor with a bactericidal action. It inhibits both topoisomerase II (Gram -) and topoisomerase IV (Gram +) bacteria. It is resistant to beta lactamases and other inactivating enzymes. It has a long half life, which allows for once a day dosing. [3]

This case presents a rare form of erysipelas penis combined with urethritis, successfully treated with Moxifloxacin. The characteristic clinical presentation, despite the unusual localization, history and microbiologic culture has been instrumental for establishing the diagnosis.

\section{REFERENCES:}

1. Марина С., Киров Г., Еризипел, монограф., 1992, София. (in Bulgarian)

2. Akkilic M, Weger W, Kranke B, Komericki P. Bullous necrotic lesion of the penis. J Eur Acad Dermatol Venereol. 2006 Sep;20(8):1024-6. DOI: 10.1111/j.1468-3083.2006.01617.x CrossRef] [PubMed]

3 . Bolon MK. The newer fluoroquinolones. Med Clin North Am. 2011 Jul;95(4):793-817. DOI:10.1016/ j.mcna.2011.03.006 CrossRef] [PubMed]

4. Bonnetblanc JM, Bedane C. Erysipelas: recognition and management. Am J Clin Dermatol. 2003; 4(3):157-63. [PubMed]

5. Caetano M, Amorin I. Erysipelas. Acta Med Port. 2005 Sep-Oct;18(5):38593. Epub 2005 Oct 16. (Article in Portuguese) [PubMed]

6. Czarnecki L, Franke-Nawrocka
I, Klobut Z. Diphtheria of the glans penis with coexistent erysipelas of the right inguinal fold in a 51-year-old man. Pol Tyg Lek. 1967 Apr 3;22(14):518-20. (in Polish) [PubMed]

7. Herpertz U.Erysipelas and lymphedema.Fortschr Med. 1998 Apr 30;116(12):36-40. (in German) [PubMed]

8. Laugier P, Gille P, Gondy G. Recurrent erysipelas of the genitalia with onset of elephantiasis. Lymphographic study. Surgical excision - graft. Bull Soc Fr Dermatol Syphiligr. 1963 Jul-Aug;70:490-1. [in French] [PubMed] 9. Joly-Guillou, ML, S. Lasrry. Practical recommendations for the drug treatment of bacterial infections of the male genital tract including urethritis, epididimitis and prostatitis. Drugs. 1999 May;57(5):743-750. [PubMed]
10. Kinn AC, Eld J. Acute erysipelatous oedema in the scrotum. Scand J Urol Nephrol. 2003;37(4):366-7. [PubMed]

11. Krasagakis K, et al. Analysis of epidemiology, clinical features and management of erysipelas. Int J Dermatol. 2010 Sep;49(9):1012-1017. DOI: $10.1111 / j .1365-4632.2010 .04464 . x$ CrossRef] [PubMed]

12. Krasagakis $\mathrm{K}$, et al. Local complications of erysipelas: a study of associated risk factors. Clin Exp Dermatol. 2011 Jun;36(4):351-354. DOI: 10.1111/j.1365-2230.2010.03978.x CrossRef] [PubMed]

13. O'Dell ML. Skin and wound infections: an overview. Am Fam Physician. 1998 May 15;57(10):2424-32. [PubMed]

\author{
Address for correspondence: \\ Ilko Bakardzhiev, MD, Ph D \\ Medical College, Medical University of Varna \\ 84, Tzar Osvoboditel str., Varna, Bu;garia \\ e-mail: varna2008@gmail.com
}

